\title{
PAGAMENTO POR SERVIÇOS AMBIENTAIS NO EXTREMO SUL DA BAHIA: O CASO DO PROGRAMA ARBORETUM DE CONSERVAÇÃO E RESTAURAÇÃO DA DIVERSIDADE FLORESTAL
}

\author{
AUTOR: VITORIA CAROLINE GONCALVES NASCIMENTO \\ CO-AUTOR: GUINEVERRE ALVAREZ MACHADO DE MELO GOMES \\ CO-AUTOR/ORIENTADOR: FREDERICO MONTEIRO NEVES
}

\begin{abstract}
Resumo: Uma das estratégias utilizadas para reverter a degradação ambiental de ecossistemas florestais são os programas de pagamento por serviços ambientais (PSA). O objetivo deste trabalho é analisar o Programa Arboretum (PA) dentro do quadro de um programa de PSA, identificando suas potencialidades e limitações. Para tanto, essa pesquisa analisou o PA e três de seus núcleos de coleta de sementes e plantio de mudas localizados nos municípios de Itamaraju (BA) e Conceição da Barra (ES), região do corredor central da mata atlântica. A metodologia baseou-se em revisão bibliográfica e documental, além da realização de grupos focais e entrevistas semiestruturadas com os integrantes dos núcleos do PA. Os resultados mostram que o PA apresenta os elementos de um programa de PSA, mas apresenta características próprias ao realizar a capacitação técnica dos moradores de seus núcleos, viabilizando o conhecimento como promotor da conservação, restauração e valorização da floresta. Até o ano de 2019, 50 pessoas integraram a rede de mudas e sementes, tendo recebido cerca de $R \$ 302.203,76$. Sendo assim, o PA, enquanto um arranjo de PSA, vai além das trocas materiais entre o programa e as comunidades e pode ser percebido nas trocas não-materiais que o programa promove em seus núcleos comunitários.
\end{abstract}

Palavras-chave: Serviços Ecossistêmicos, PSA, Biodiversidade, Hileia Baiana. 